\title{
Top and Bottom Spin Valves With Ni-Fe-Mn Antiferromagnetic Layer
}

\author{
Ilya Blinov", Tatiana Krinitsina, Mikhail Milyaev, Vladimir Popov and Vladimir Ustinov \\ M.N. Miheev Institute of Metal Physics, 620990 Ekaterinburg, Russia
}

\begin{abstract}
Structure, magnetic and magnetoresistive properties of spin valves with $\mathrm{Ni}-\mathrm{Fe}-\mathrm{Mn}$ antiferromagnet as a pinning layer have been studied. A technique of fabrication of spin valves with an enhanced thermal stability and improved hysteretic characteristics has been elaborated.
\end{abstract}

\section{Introduction}

Bilayers of permalloy/antiferromagnetic triple Ni-Fe-Mn alloy have been studied, as well as magnetic and magnetoresistive properties of spin valves (SVs) with $\mathrm{Ni}-\mathrm{Fe}-\mathrm{Mn}$ antiferromagnet (AF) as a pinning layer. A technique of fabrication of bottom spin valves based on $\mathrm{Ni}-\mathrm{Fe}-\mathrm{Mn}$ ordered AF with an enhanced thermal stability and improved hysteretic characteristics has been elaborated.

To apply the ordered Ni-Fe-Mn AF phase in spin valves, a definite deposition order of permalloy and manganese layers is necessary. Notably, the permalloy layer should be deposited on manganese or the manganese containing alloy [1]. With this deposition order, the authors of [2] fixed the high value $H_{\mathrm{ex}}=110$ Oe after the annealing of the FeMn $(15 \mathrm{~nm}) / \mathrm{NiFe}(15 \mathrm{~nm})$ bilayers. It should be noted that the formation of this ordered system is only possible with the thermal treatment of the films that contain the permalloy and manganese layers or the layers of the manganese containing alloy. The annealing of $\mathrm{Ni}_{48} \mathrm{Fe}_{12} \mathrm{Mn}_{40}$ and $\mathrm{Ni}_{32} \mathrm{Fe}_{8} \mathrm{Mn}_{60}$ films which after magnetron sputtering from the targets of corresponding compositions, were in the state of a homogeneous ternary solid solution did not result in the formation of an ordered antiferromagnetic phase. After annealing at $400^{\circ} \mathrm{C}$, the decomposition of a ternary solid solution into the nickel based solid solution and almost pure manganese was revealed. A similar result was found in [3].

\section{Experimental details}

The samples were made by DC magnetron sputtering and by electron-beam evaporation on glass (Corning) substrates and single-crystalline sapphire (1012). To form a unidirectional anisotropy the magnetic field of 110 Oe was applied in the process of nanostructures growth, and the thermal-magnetic treatment was performed at pressure of $10^{-4} \mathrm{~Pa}$ in permanent magnetic field of $2 \mathrm{kOe}$ applied in the sample plane at $260{ }^{\circ} \mathrm{C}$ for
$4 \mathrm{~h}$. The exchange bias field temperature dependence was measured in the temperature range of $20-260{ }^{\circ} \mathrm{C}$. Etching of samples for preparation of bottom SVs was carried out in a device for reactive ion-plasmic etching PlasmaPro NGP 80 RIE Oxford.

\section{Results and discussion}

According to the results of the studies carried out, the bilayers with antiferromagnetic triple alloy $\mathrm{Ni}_{14} \mathrm{Fe}_{6} \mathrm{Mn}_{80}$ are characterized by medium blocking temperature $T_{\mathrm{b}}=$ $150{ }^{\circ} \mathrm{C}$ (Fig. 1) and moderate energy of exchange interaction $J_{\mathrm{ex}}=0.05 \mathrm{erg} / \mathrm{cm}^{2}$ [4].

Higher $T_{\mathrm{b}}=270{ }^{\circ} \mathrm{C}$ (Fig. 1) and $J_{\mathrm{ex}}=0.27 \mathrm{erg} / \mathrm{cm}^{2}$ were obtained for the annealed manganese/permalloy bilayers. In this case, an ordered AF phase of Ni-Fe-Mn is formed [5]. The ordered $\mathrm{AF}$ phase formation is testified by an appearance of super-structural Debye rings (100), (110), (210), (211) (indicated by arrows in Fig. 2a) in electron diffraction patterns of sample $\mathrm{Al}_{2} \mathrm{O}_{3} / \mathrm{Mn}(50 \mathrm{~nm}) / \mathrm{Ni}_{77} \mathrm{Fe}_{23}(30 \mathrm{~nm}) / \mathrm{Ta}(5 \mathrm{~nm})$ after its annealing in the magnetic field at $T_{\text {ann }}=260{ }^{\circ} \mathrm{C}$ for $4 \mathrm{~h}$. In this case in the electron-microscope images one can see the columnar structure, and an intermediate layer between manganese and permalloy layers is absent (Fig. 2b).

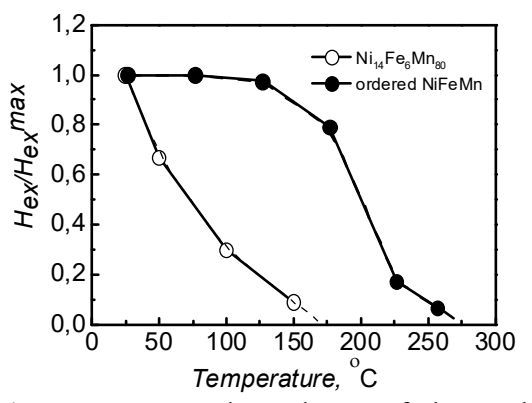

Fig. 1. Temperature dependence of the exchange bias field $\left(H_{\mathrm{ex}}\right)$ for two types of AF used. 


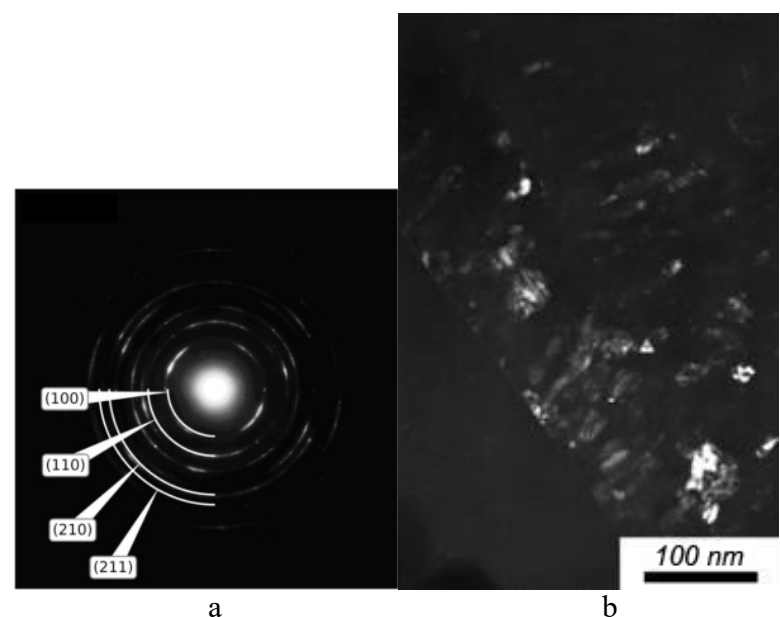

Fig. 2. Electron diffraction pattern (a) and dark-field image in (100) reflection (b) of a cross section TEM image of $\mathrm{Al}_{2} \mathrm{O}_{3} / \mathrm{Mn}(50 \mathrm{~nm}) / \mathrm{Ni}_{77} \mathrm{Fe}_{23}(30 \mathrm{~nm}) / \mathrm{Ta}(5 \mathrm{~nm})$ after thermalmagnetic treatment at $260{ }^{\circ} \mathrm{C}$ for $4 \mathrm{~h}$. Super-structural reflections are shown by arrows.

Based on the ordered AF Ni-Fe-Mn phase the spin valves with an enhanced thermal stability can be fabricated.

As shown by the studies of the effect of the AF layer $\mathrm{Ni}_{14} \mathrm{Fe}_{6} \mathrm{Mn}_{80}$ thickness on the magnetoresistance and shift of the pinned layer $\mathrm{Co}_{90} \mathrm{Fe}_{10}$ loop of the top spin valve

glass $/ \mathrm{Ta} / \mathrm{Ni}_{80} \mathrm{Fe}_{20} / \mathrm{Co}_{90} \mathrm{Fe}_{10} / \mathrm{Cu} / \mathrm{Co}_{90} \mathrm{Fe}_{10} / \mathrm{Ni}_{14} \mathrm{Fe}_{6} \mathrm{Mn}_{80} / \mathrm{Ta}$, the combination of maximal values of magnetoresistive effect and pinned layer $\mathrm{Co}_{90} \mathrm{Fe}_{10}$ loop shift is observed at $t_{\mathrm{AF}}=25 \mathrm{~nm}$. At this thickness $\left(\Delta R / R_{\mathrm{s}}\right)=6.95 \%$.

To study the magnetoresistance dependence of a spin valve on the copper layer thickness the samples with $t_{\mathrm{AF}}=25 \mathrm{~nm}$ were prepared.

With increasing copper layer thickness the magnetoresistance $\Delta R / R_{\mathrm{s}}$ at first increases and then decreases [4]. The dependence obtained is nonmonotone and demonstrates qualitative agreement with the data published in [6].

The maximal value of $\Delta R / R_{\mathrm{s}}=7.30 \%$ corresponds to $t_{\mathrm{Cu}}=2.8 \mathrm{~nm}$ (Fig. 3). The magnetoresistance sensitivity determined as an average value for the ascending and descending hysteresis loop of the free layer $\mathrm{Ni}_{80} \mathrm{Fe}_{20} / \mathrm{Co}_{90} \mathrm{Fe}_{10}$ is $\Delta\left(\Delta R / R_{\mathrm{s}}\right) / \Delta H=0.75 \% / \mathrm{Oe}$. The data obtained demonstrate possibility of using disordered alloy $\mathrm{Ni}_{14} \mathrm{Fe}_{6} \mathrm{Mn}_{80}$ as a pinning layer in top spin valves.

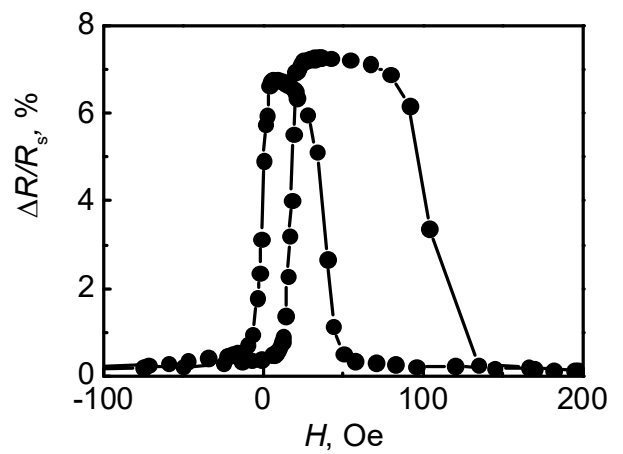

Fig. 3. Field dependence of magnetoresistance of a top spin valve glass $/ \mathrm{Ta}(5 \mathrm{~nm}) / \mathrm{Ni}_{80} \mathrm{Fe}_{20}(2 \mathrm{~nm}) / \mathrm{Co}_{90} \mathrm{Fe}_{10}(5.5 \mathrm{~nm}) / \mathrm{Cu}(2.8$ $\mathrm{nm}) / \mathrm{Co}_{90} \mathrm{Fe}_{10}(5.5 \mathrm{~nm}) / \mathrm{Ni}_{14} \mathrm{Fe}_{6} \mathrm{Mn}_{80}(25 \mathrm{~nm}) / \mathrm{Ta}(3 \mathrm{~nm})$.
To fabricate a bottom SV with the ordered AF phase $\mathrm{Ni}-\mathrm{Fe}-\mathrm{Mn}$ a technological cycle has been worked out, including the following operations:

1) Formation of the ordered AF phase Ni-Fe-Mn in a sample

$\mathrm{Al}_{2} \mathrm{O}_{3} / \mathrm{Ni}_{77} \mathrm{Fe}_{23}(5 \mathrm{~nm}) / \mathrm{Mn}(50 \mathrm{~nm}) / \mathrm{Ni}_{77} \mathrm{Fe}_{23}(30 \mathrm{~nm}) / \mathrm{Ta}(5$ $\mathrm{nm})$ by the thermal- magnetic treatment at $260{ }^{\circ} \mathrm{C}$ for 4 $\mathrm{h}$.

2) Ion etching for $20 \mathrm{~min}$ of the annealed sample for the surface layer removing.

The ion etching duration was chosen to assure the removal of the contaminated surface layer and retaining the ferromagnetic area together with the ordered AF phase required for the formation of the unidirectional anisotropy in the FM layer sputtered on the sample after etching.

3) Magnetron sputtering of the layered structure consisting of ferromagnetic $\mathrm{CO}_{90} \mathrm{Fe}_{10}$ layers separated by $\mathrm{Cu}$ on the as-prepared sample $\mathrm{Al}_{2} \mathrm{O}_{3} / \mathrm{Ni}-\mathrm{Fe}-\mathrm{Mn}$.

4) Annealing of the as-prepared structure in a magnetic field at $T_{\text {ann }}=300{ }^{\circ} \mathrm{C}$ for $15 \mathrm{~min}$, the annealing temperature $T_{\mathrm{ann}}=300{ }^{\circ} \mathrm{C}$ being higher than $T_{\mathrm{b}}=270^{\circ} \mathrm{C}$ for $\mathrm{Al}_{2} \mathrm{O}_{3} / \mathrm{Ni}_{77} \mathrm{Fe}_{23}(5 \mathrm{~nm}) / \mathrm{Mn}(50 \mathrm{~nm}) / \mathrm{Ni}_{77} \mathrm{Fe}_{23}(30 \mathrm{~nm}) /$ $\mathrm{Ta}(5 \mathrm{~nm})$.

The magnetoresistance of the as-fabricated spin valve $\mathrm{Al}_{2} \mathrm{O}_{3} / \mathrm{Ni}-\mathrm{Fe}$ -

$\mathrm{Mn} / \mathrm{Co}_{90} \mathrm{Fe}_{10}(5.5 \mathrm{~nm}) / \mathrm{Cu}(3.6 \mathrm{~nm}) / \mathrm{Co}_{90} \mathrm{Fe}_{10}(5.5 \mathrm{~nm}) / \mathrm{Ta}(5$ $\mathrm{nm}$ ) is $\Delta R / R_{\mathrm{s}}=3.8 \%$ (Fig. 4). This value is significantly higher than the effect obtained in [1], since the replacement of permalloy in the free and pinning layer by $\mathrm{Co}$ or the $\mathrm{Co}_{90} \mathrm{Fe}_{10}$ alloy leads to an increase in spindependent scattering and an increase in the giant magnetic resistance effect (GMR) in the spin valves [7].

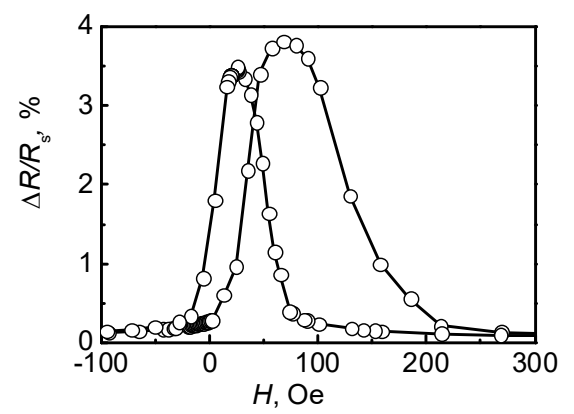

Fig. 4. Field dependence of the magnetoresistance of bottom spin valve $\mathrm{Al}_{2} \mathrm{O}_{3} / \mathrm{Ni}-\mathrm{Fe}-\mathrm{Mn} / \mathrm{Co}_{90} \mathrm{Fe}_{10}(5.5 \mathrm{~nm}) / \mathrm{Cu}(3.6 \mathrm{~nm}) /$ $\mathrm{Co}_{90} \mathrm{Fe}_{10}(5.5 \mathrm{~nm}) / \mathrm{Ta}(5 \mathrm{~nm})$.

\section{Conclusion}

A possibility of application of the Ni-Fe-Mn AF for SV devices is demonstrated on a sample of composition $\mathrm{Ta} / \mathrm{Ni}_{80} \mathrm{Fe}_{20} / \mathrm{Co}_{90} \mathrm{Fe}_{10} / \mathrm{Cu} / \mathrm{Co}_{90} \mathrm{Fe}_{10} / \mathrm{Ni}_{14} \mathrm{Fe}_{6} \mathrm{Mn}_{80} / \mathrm{Ta} . \quad \mathrm{A}$ technology of fabrication of a spin valve based on the ordered AF phase Ni-Fe-Mn has been worked out. A spin valve with giant magnetic resistance exceeding the GMR of previously known structures has been created, 
and the possibility of using the ordered AF phase Ni-Fe$\mathrm{Mn}$ as a pinning layer in a spin valve has been proved.

The research has been done within the state assignment of FASO of Russia (theme "Spin", with partial support by UB RAS (project No. 18-10-2-3) and RFBR (project No. 16-3200128).

\section{References}

1. A.V. Svalov, V. O. Vas'kovskii, and Yu. M. Yarmoshenko, Fiz. Met. Metalloved. 79, 270 (1995)

2. K.C. Chen, C.T. Yang, Y. H. Wu, C.H. Huang, K.M. Wu, J. C. Wu, S. L. Young, and L. Horng, Phys. Status Solidi C 4, 4372 (2007).

3. C. S. Yoon, S. J. Kim, S. J. Kim, and C. R. Kim, J. Appl. Phys. 94, 539 (2003)

4. I. V. Blinov, T. P. Krinitsina, M. A. Milyaev, V. V. Popov, V. V. Ustinov, Sol. Stat. Phenomena 233-234, 517 (2015)

5. I. V. Blinov, T. P. Krinitsina, S. A. Matveev, M. A. Milyaev, P. N. Sedova, V. V. Popov, V. V. Ustinov, J. Nanosci. Nanotech. 12, 7562 (2012)

6. V.V. Ustinov, M.A. Milyaev, L.I. Naumova, V.V. Proglyado, N.S. Bannikova, T.P. Krinitsina, Physics of Metals and Metallography 113, 341 (2012)

7. Coehoorn, R. Giant Magnetoresistance and Magnetic Interactions in Exchange-Biased SpinValves, in: K.H.J. Buschow (Ed.), Handbook of magnetic materials 15 - Elsevier B.V., Amsterdam, P.1 - 199 (2003) 